\title{
Accumulation of ceroid in smooth muscle indicates severe malabsorption and vitamin E deficiency
}

\author{
G W H STAMP, D J EVANS
}

From the Department of Histopathology, Royal Postgraduate Medical School, Hammersmith Hospital, London

SUMMARY Four patients had accumulation of ceroid in smooth muscle (lipofuscinosis), which indicated severe or uncontrolled malabsorption, with confirmed vitamin $\mathrm{E}$ deficiency in three cases. The distribution of the pigment was systematic, and there seemed to be an association between malabsorption syndrome and vitamin E deficiency. Vitamin E supplementation seems to be indicated in such patients, and it is suggested that studies of smooth muscle function should be made in cases of heavy accumulation of ceroid.

Accumulation of ceroid pigment in intestinal smooth muscle (lipofuscinosis or brown bowel syndrome) is an association of malabsorption syndromes, but systemic ceroid deposition in vascular or other smooth muscle has only occasionally been documented in man. ${ }^{1-4}$ We report four cases in which a malabsorption syndrome or vitamin $\mathrm{E}$ deficiency was inferred from surgical biopsy material, an inference that has therapeutic implications.

\section{Case reports}

\section{CASE 1}

A 30 year old man came to surgery with a history of "Noonan's syndrome." Histological examination showed atrophic testes with Sertoli cell nodules, and no evidence of malignancy. Ceroid was noted in smooth muscle cells of vasa deferentia and small arteries and veins of the spermatic cord (fig 1). Although haematoxylin and eosin stained sections had shown that the material was lipofuscin, this was confirmed. The pigment stained strongly with periodic acid Schiff and was resistant to diastase digestion. It also stained with methylene blue, methenamine silver, and Masson-Fontana, and was distinguished from melanin by its positive staining with Sudan black and the long Ziehl-Neelsen technique using a picric acid counterstain (as the usual methylene blue counterstain masks the fuchsinophilia). ${ }^{3}$ Orange autofluorescence is another property of lipofuscin, ${ }^{5}$ and this was

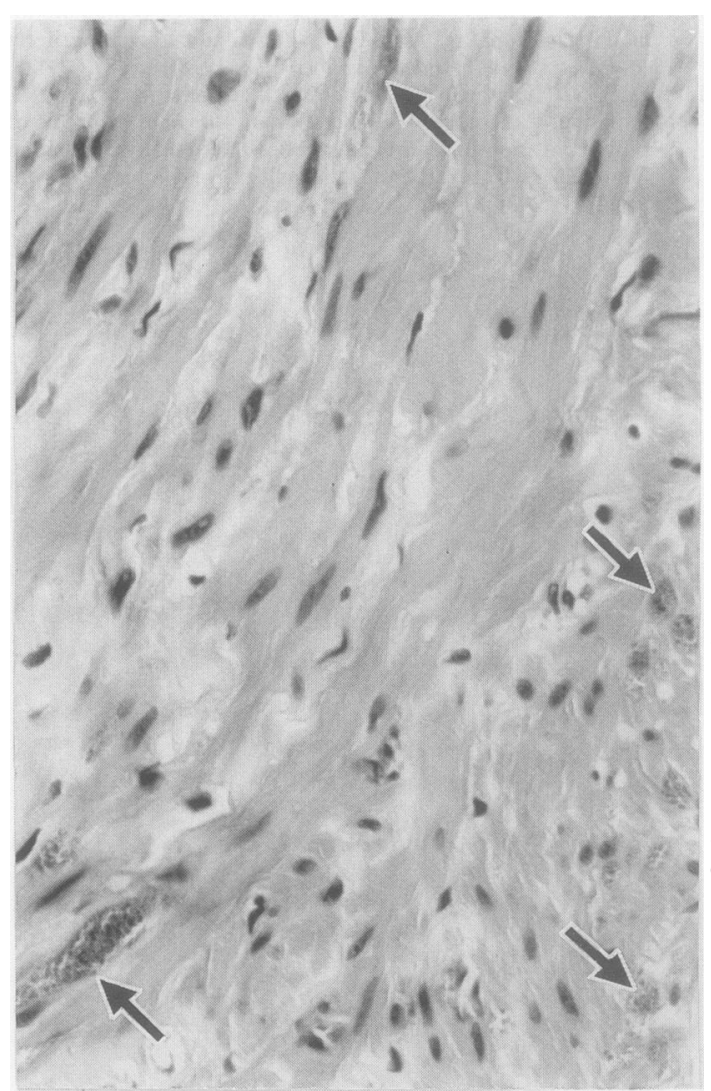

Fig 1 Ceroid in smooth muscle of vas deferens (arroved). (Haematoxylin and eosin.) 
observed on unstained sections. Finally, Perls's stain for iron pigment yielded negative results. This panel of stains were performed in all the cases reported here.

Further enquiries showed that he had had a four year history of diarrhoea and steatorrhoea. Multiple nutritional deficiencies had been documented with faecal fat ranging from 5-30 g/24 hours (normal less than 7) and a protein losing enteropathy $\left(\mathrm{Cr}^{51} 4.7 \%\right.$ loss in four days; normal less than $0.08 \%$ ). Pronounced sacral oedema and lower limb oedema was present, and a pedal lymphangiogram showed lymphangiectasia, which was also present in the jejunal biopsy specimen (fig 2). Intestinal lymphangiectasia is associated with malabsorption and relatively severe vitamin $\mathrm{E}$ deficiency. ${ }^{6}$ Intestinal lymphangiectasia has been documented in Noonan's syndrome (also called "male Turner's syndrome") and is presumably a consequence of the generalised disturbance in lymphatic drainage that often occurs. ${ }^{7}$

Following the histological findings in the testis, vitamin $\mathrm{E}$ concentrations were measured and found

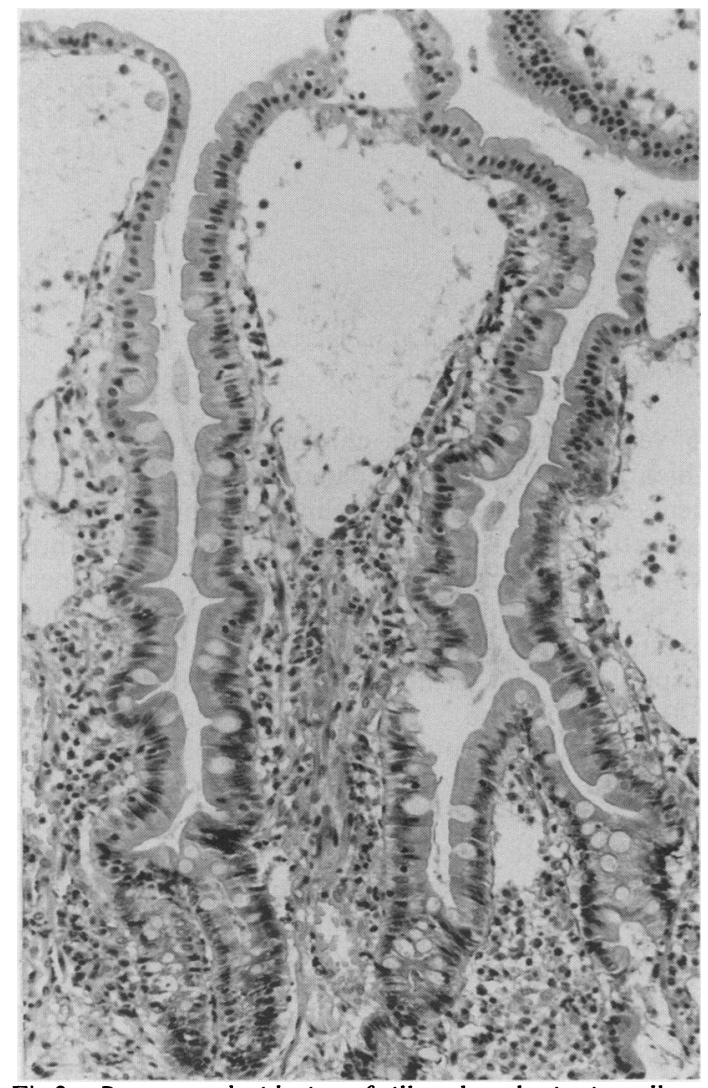

Fig 2 Pronounced widening of villous lymphatics in well orientated jejunal biopsy specimen. Spaces are clearly lined by endothelium. (Haematoxylin and eosin.)

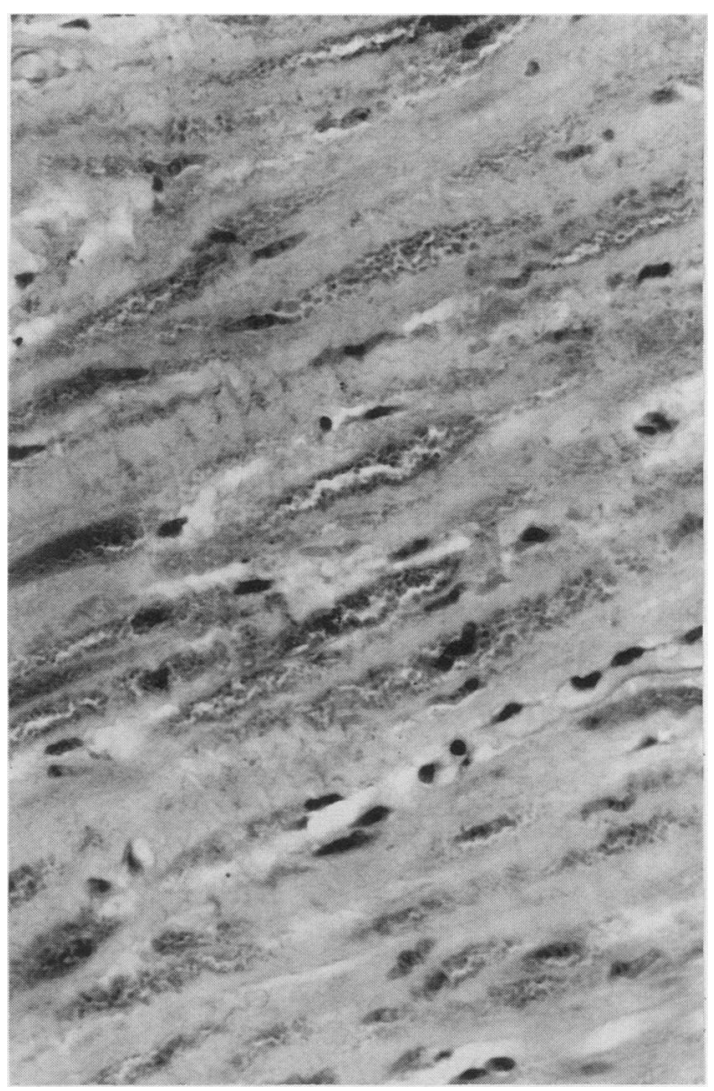

Fig 3 Staining accentuates ceroid pigmentation in smooth muscle of oesophageal wall. (Periodic acid Schiff.)

to be low at $4 \cdot 0 \mu \mathrm{mol} / 1(\mathrm{n}=11 \cdot 5-35)$. Prophylactic vitamin $\mathrm{E}$ supplements were added to the patient's dietary regimen.

CASE 2

An oesophagogastrectomy specimen from a 53 year old man was submitted for surgical pathology. He had had a clinical history of dysphagia of three months duration. Macroscopically there was a large annular tumour, $0.5 \mathrm{~cm}$ above the oesophagogastric junction, extending to within $1.5 \mathrm{~cm}$ of the proximal margin. Microscopically, the tumour was a poorly differentiated carcinoma extending through the wall of the oesophagus. Heavy ceroid pigmentation was noted in the muscularis propria (fig 3 ). The patient had had bouts of steatorrhoea for eight years. A jejunal biopsy specimen showed severe partial villous atrophy. Initially, he responded to a gluten free diet, but he subsequently deteriorated, with complaints of weight loss and chest pain, and clinical hepatomegaly. He died four months postoperatively.

Necropsy showed local recurrence of the 
oesophageal carcinoma and secondary deposits in lymph nodes, liver, and vertebrae. Extensive lipofuscinosis was noted both macroscopically and microscopically in oesophagus, small bowel, colon and heart. Ceroid pigment was shown in many arteries and veins. The jejunum and ileum showed extensive villous atrophy. This may well be an example of coeliac disease complicated by oesophageal carcinoma, but formal histological proof of a response to gluten withdrawal could not be obtained.

\section{CASE 3}

A specimen of jejunum from refashioning of choledochojejunostomy from a 37 year old man was submitted for surgical pathology. Histological examination showed a very heavy accumulation of ceroid in the muscularis mucosae, muscularis propria, and submucosal blood vessels (fig 4). The mucosal villous architecture was normal.

The patient had undergone total pancreatectomy

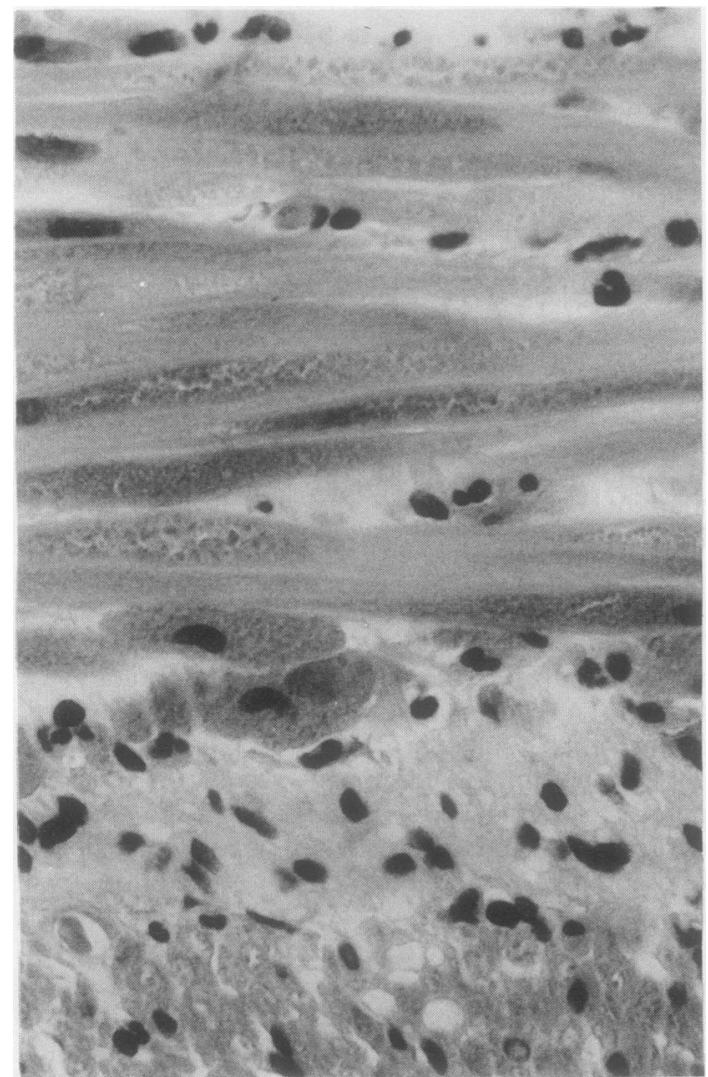

Fig 4 Accumulation of ceroid in muscularis propria.

Pigment is present in both layers but is much easier to identify in longitudinally sectioned fibres. (Haematoxylin and eosin.)

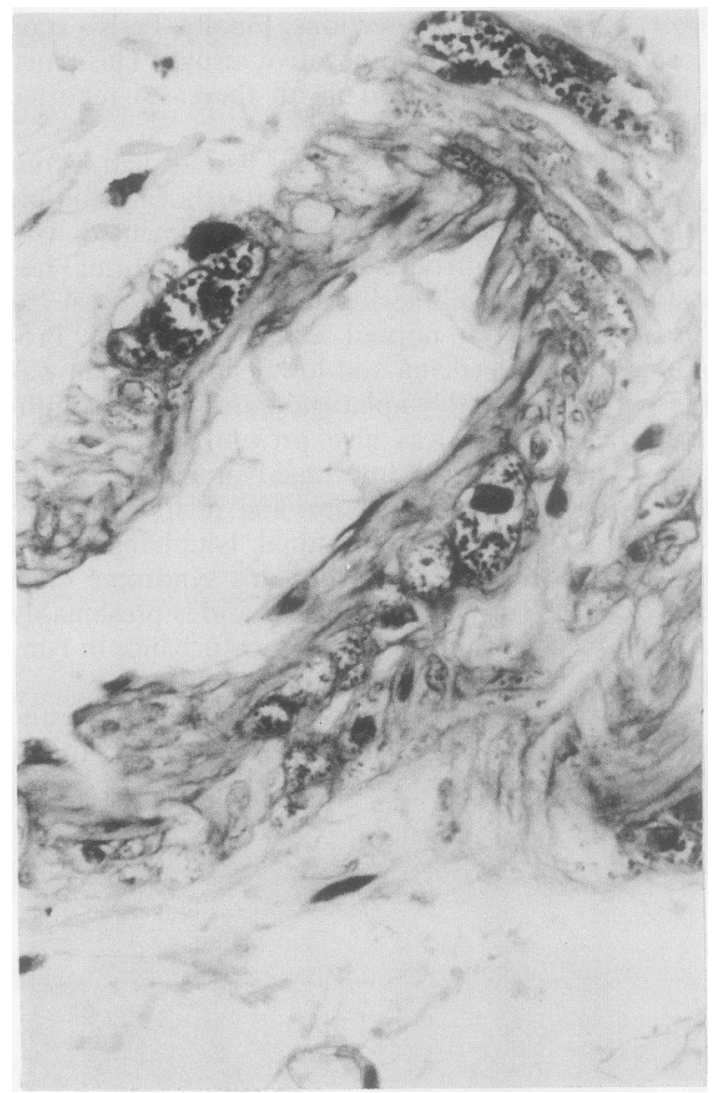

Fig 5 Ceroid within wall of submucosal blood vessel. (Periodic acid Schiff.)

15 years previously for chronic pancreatitis, after which he had been given pancreatic enzyme supplements and replacement insulin. His only symptoms were attacks of ascending cholangitis beginning three years prior to admission to hospital in this instance.

The extent of malabsorption was not fully investigated as the patient was referred from another hospital, but the serum albumin was $38 \mathrm{~g} / \mathrm{l}$, calcium $2.20 \mu \mathrm{mol} / 1$, and haemoglobin concentration $13 \cdot 1 \mathrm{~g} / \mathrm{dl}$. Malabsorption was presumably due to pancreatic enzyme deficiency, possibly exacerbated by biliary insufficiency as a consequence of the recurrent cholangitis. He made an uneventful postoperative recovery and remained asymptomatic. Vitamin $\mathrm{E}$ concentrations were measured on request twelve months postoperatively and found to be low at $\stackrel{?}{?}$ $3 \cdot 3 \mu \mathrm{mol} / 1$.

\section{CASE 4}

A jejunal biopsy specimen from a 71 year old man was assessed for coeliac disease. The biopsy specimen showed severe partial villous atrophy, with pro- 
nounced accumulation of ceroid in the muscularis mucosae and lamina propria, and in a small submucosal blood vessel (fig 5).

Coeliac disease had been diagnosed 10 years previously. Intermittent bouts of steatorrhoea had occurred since then, which the patient admitted were related to poor dietary compliance. This was exacerbated after the death of his wife six months earlier. He was found to be cachectic with generalised muscular weakness. Investigation showed that the haemoglobin concentration was $10.2 \mathrm{~g} / \mathrm{dl}$ (mean corpuscular volume, $107 \mathrm{fl}$ ), albumin $27 \mathrm{~g} / \mathrm{dl}$, magnesium $0.74 \mathrm{mmol} / \mathrm{l}$. Vitamin $\mathrm{E}$ concentrations were undetectable, a highly unusual finding.

During the course of his admission he developed signs of subacute intestinal obstruction, attributed to faecal impaction in the sigmoid colon. His general condition did not improve, and although further investigations were planned, the patient discharged himself against advice. Two weeks later he died at home of extensive burns, having been unable to turn off the hot tap while in his bath.

\section{Discussion}

Accumulation of ceroid (lipofuscinosis) occurs in smooth muscle of the bowel in malabsorption syndromes, ${ }^{18}$ and may be so severe that it is visible macroscopically (so called "brown bowel syndrome"). ${ }^{9}$ Vascular disease is much less conspicuous and has only occasionally been described in man, ${ }^{134}$ although generalised ceroidosis is well documented in experimental animals, ${ }^{10}$ in whom there is a clear cut association between vitamin $\mathrm{E}$ deficiency and accumulation of ceroid. ${ }^{1011}$ It is thought that vitamin $E$ has an important protective role in mitochondria, complementing the effect of selenium (a constituent of glutathione reductase) in preventing the unsaturated lipids of the mitochondrial membrane being damaged by free radicals formed during oxidative phosphoxylation. ${ }^{2}$ In vitamin $\mathrm{E}$ deficiency the accumulation of ceroid can be shown to be intramitochondrial by electron microscopy. ${ }^{212}$ In rats, which are made deficient of vitamin $E$ or selenium, subsequent adminstration can prevent the accumulation of lipid peroxidation products. ${ }^{13}$

The major role of vitamin $\mathrm{E}$ in man concerns the maintenance of normal neurological function. The most severe deficiencies occur in abetalipoproteinaemia and are associated with ataxic neuropathy and pigmentary retinopathy. ${ }^{14}$ The benefits of vitamin $\mathrm{E}$ supplementation have been convincingly shown. ${ }^{14} 15$ Other malabsorptive states have been associated with spinocerebellar degeneration, attributed to vitamin E deficiency. ${ }^{1617}$

Neuropathological studies in vitamin E deficient subjects, monkeys, and rats have shown axonal degeneration in the posterior columns, with selective loss of large calibre myelinated sensory axons in the spinal cord and peripheral nerves. ${ }^{18}$ Cardiomyopathy and skeletal myopathy have been repeatedly shown in experimental animals, but only on rare occasions has a similar association been noted in man. ${ }^{419}$ Smooth muscle function has not been adequately investigated either in experimental animals or in man, although various authors have suggested that it might be permanently impaired. ${ }^{1320}$

The identification of accumulation of ceroid may have two distinct implications: (i) the patient has or has had a malabsorption syndrome; (ii) vitamin E deficiency is, or was, present and should be an indication for evaluating the nutritional status and serum vitamin E concentrations. It may indicate poor compliance (as in cases 1 and 4), or malabsorption which may not be clinically manifest (case 3 ). In cases in which vitamin $\mathrm{E}$ deficiency is shown, it seems perverse to withhold a treatment, which, in suitable doses, is harmless ${ }^{21}$ and may prevent occasional serious complications.

It is not clear to what extent the effects of vitamin $\mathrm{E}$ deficiency are reversible. Disappearance of ceroid after vitamin $E$ supplementation has only rarely been described, ${ }^{22}$ and the time scale is not established. It seems clear, however, that ceroidosis is not itself an adequate reflection of current vitamin $\mathrm{E}$ concentrations, but indicates an extended episode of deficiency that requires full clinical evaluation.

We thank Dr DPR Muller, at the Institute of Child Health, University of London, for arranging vitamin E estimation and for his valuable advice, and Mrs P Weller for excellent secretarial help.

\section{References}

1 Fox B. Lipofuscinosis of the gastrointestinal tract in man. J Clin Pathol 1967;20:806-13.

2 Foster CS. The brown bowel syndrome: a possible smooth muscle mitochrondrial myopathy? Histopathol 1979;3:1-17.

3 Gallagher RL. Intestinal ceroid deposition-"Brown bowel syndrome". Virchows Arch (Pathol Anat) 1980;389:143-51.

4 Saito K, Saburo M, Yokoyama T, Okiniwa M, Shigehiko K. Pathology of chronic vitamin E deficiency in fatal familial intrahepatic cholestasis (Byler disease). Virchows Arch (Pathol Anat) 1982;396:319-30.

5 Rost FWD, Pearce AGE. Fluorescence microscopy. In: Histochemistry-theoretical and applied. 4th ed. Vol 1. Edinburgh: Churchill Livingstone, 1980:346-78.

6 MacMahon MT, Neale G. The absorption of $\alpha$-tocopherol in control subjects and in patients with intestinal malabsorption. Clin Sci 1970;38:197-210.

7 Herzog DB, Logan R, Kooistra JB. The Noonan syndrome with intestinal lymphangiectasia. J Pediatr 1976;88(2):270-2.

8 Muller DPR, Harries JT, Lloyd JK. The relative importance of the factors involved in the absorption of vitamin $\mathrm{E}$ in children. Gut 1974;15:966-71. 
9 Toffler AH, Hukill PB, Spiro HM. Brown bowel syndrome. Ann Intern Med 1963;58 (5):872-7.

10 Cordes DO, Mosher AH. Brown pigmentation (lipofuscinosis) of canine intestinal muscularis. J Pathol Bacteriol 1966;92: 197-206.

11 Mason KE, Telford IR. Some manifestations of vitamin E deficiency in the monkey. Arch Pathol 1947;43:363-73.

12 Lambert JR, Luk SC, Pritzker KPH. Brown bowel syndrome in Crohn's disease. Arch Pathol Lab Med 1980;104:201-5.

13 Dougherty JJ, Hoekstra WG. Effects of vitamin E and selenium on copper-induced lipid peroxidation in vivo and on acute copper toxicity. Proc Soc Exp Biol Med 1982;169:201-8.

14 Herbert PN, Gotto AM, Fredrickson DS. Familial lipoprotein deficiency. In: Stanbury JB, Wyngaarden JB, Frederickson DS, eds. The metabolic basis of inherited diseases. 4th ed. New York: McGraw-Hill, 1978.

15 Muller DPR. Vitamin E-its role in neurological function. Postgrad Med J 1986;62:107-12.

16 Harding AE, Muller DPR, Thomas PK, Willison HJ. Spinocerebellar degeneration secondary to chronic intestinal malabsorption: a vitamin E deficiency syndrome. Ann Neurol 1982;12:419-24.

17 Bertoni JM, Abraham FA, Falls HF, Itabashi HH. Small bowel resection with vitamin $\mathrm{E}$ deficiency and progressive spinocerebellar syndrome. Neurology 1984;34:1046-52.

18 Nelson JS, Fitch CD, Fischer VW, Brown GD, Chou AC. Progressive neuropathologic lesions in vitamin E deficient rhesus monkeys. J Neuropathol Exp Neurol 1981;40:166-86.

19 Neville HE, Ringel SP, Guggenheim MA, Wheling CA, Starcevich JM. Ultrastructural and histochemical abnormalities of skeletal muscle in patients with chronic vitamin $\mathrm{E}$ deficiency. Neurology 1983;33:483-8.

20 Hosler JP, Kimmel KK, Moeller DD. The "brown bowel syndrome": a case report. Am J Gastroenterol 1982;77(ii):854-5.

21 Roberts HJ. Perspective on vitamin $\mathrm{E}$ as therapy. JAMA 1981;246:129-31.

22 Lee SP, Nicholson GI. Ceroid enteropathy and vitamin E deficiency. NZ Med J 1976;83:318-20.

Requests for reprints to: Dr GWH Stamp, Department of Histopathology, Royal Postgraduate Medical School, Hammersmith Hospital, Du Cane Road, London W12 0HS, England. 